\title{
Does Nifty Index Inclusion (still) Convey Information? A Comprehensive Empirical Examination in the Indian Stock Market
}

\author{
Dr Srikanth Parthasarathy \\ Associate Professor \\ Rajalakshmi School of Business, Chennai-600124 \\ Tel: 98-8480-6248Ｅ- mail: psrikanth2011@gmail.com
}

\author{
Received: Jan. 9, 2019 Accepted: Feb. 24, $2019 \quad$ Published: June 1, 2019 \\ doi:10.5296/ajfa.v11i1.14866 URL: https://doi.org/10.5296/ajfa.v11i1.14866
}

\begin{abstract}
The objective of this study is to conduct a comprehensive empirical examination of the S\&P CNX Nifty index additions, for the complete period (2000 - 2018), first sub period (2000-2009) and second sub period (2010-2018), using both the price and non-price effects and the explanations surrounding them in the Indian stock market. This event methodology is used with three abnormal return computational methods, around the announcement and inclusion dates of index addition, in order to improve the robustness and reliability of the results. The results show that the Nifty index additions are associated with significant permanent abnormal returns in the complete, first and second period. However, the index effect has diminished in the second period. The information related explanations dominate in the complete and first period. The second period finds support for the downward sloping demand curve hypothesis. I extend the existing literature to a hitherto unexplored new sample period (2010-2018) in order to examine the price and non-price effects around Nifty index additions.
\end{abstract}

Keywords: India, Financial markets, Index inclusions, Nifty Index, Demand curves 


\section{Introduction}

The index inclusion effects have fascinated researchers and the price effects are well documented since 1986 in developed economies and since 2000 in the emerging economies. The earlier research focused mainly on the price effects, however, the recent research have additionally considered the non-price attributes like liquidity, information and other attributes. The index inclusion effect is interesting, as apparently the index inclusion is an information free event because the decision to include stocks into index is made using publicly available information. If information content is not the primary explanation, it provides a perfect setting to examine whether stocks have horizontal demand curves. This has important implications as one of the key assumptions in finance theory is the horizontal demand curve in which investors can buy and sell stocks without affecting the price. The two pillars of modern finance, the Modigliani Miller theorem (MM) (Modigliani and Miller, 1958) and the Capital asset pricing models (CAPM) (Sharpe, 1964) predict horizontal demand curves for stocks. The home leverage explanation of MM and efficient market hypothesis (EMH), the foundation stone of CAPM, assume horizontal demand curves for stocks.

If stocks have long term downward sloping demand curve (DSDC hypothesis), the added stocks face increased demand and buying pressure which cannot be satisfied without a shift in the demand curve, as stocks are not perfect substitutes. Then the price effects following index additions should be permanent as evidenced by Shleifer (1986), Lynch and Mendenhall (1987) and Wurgler and Zhuravskya (2002). The short run downward sloping curve implies that the price effects are due to the short term demand of the index funds tracking the index. The stock prices will revert back to its original level once the index funds complete their portfolio rebalancing to track the index (Price Pressure Hypothesis, PPH). The evidence by Harris and Gurel (1986) and Vespro (2006) is consistent with this hypothesis.

The price effects following index additions, however, are also consistent with horizontal demand curves, if the price effects are due to increase in expected cash flow or due to reduction in the discount rate. The increase in expected cash flow can happen if index additions convey positive information about the prospects of the firm (certification hypothesis, Jain (1987) and Dhillon and Johnson (1991)). Next, investor awareness or greater interest in the stocks added to an index could be the reason for increase in expected cash flow if companies are forced to become more efficient due to increased monitoring by investors and analysts (Denis et al. (2003) and Chen et al. (2004). The decrease in discount rate can happen if liquidity improves post index addition. Increased interest in index stocks may cause more efficient information production leading to reduced information asymmetry and consequently improved liquidity (Amihud and Mendelson (1986), Chen et al. (2003) and Hradzil et al. (2007)).

EMH asserts that all information, both public and private, is reflected in the stock prices quickly. The implication is that active portfolio management is useless, as it will be impossible to use the information to make consistent economic gains. The ascendancy of this paradigm caused a shift from the active to passive investment strategies like the index funds. Consequently, this could lead to buying and selling pressure during index revisions leading to 
significant price effects. Further, EMH asserts that all public information will be quickly and correctly incorporated in the stock prices. Hence, the index addition announcements, made with public available information, should not have any impact on the prices. Even if we assume information content in Index additions, the information should be quickly reflected in the prices. Therefore, this empirical examination also has implications for the market efficiency in the Indian stock market. These studies on index inclusion, providing clarity on the price and non-price effects, have important implications for both the investors, investment managers and corporate finance managers alike. Further, the managers of companies can prioritise their choices and decision-making depending on its impact and importance.

This study examines the price and trading volume changes in the Nifty index constituents using a sample of 50 index additions for the complete period between April 2000 and March 2018. Also, the full sample is further divided into sub periods namely, March 2000 to December 2009 and January 2010 to March 2018 in order to examine the price and trading volume changes in the sub periods and delineate the various explanations surrounding index additions in the subperiods.

The objective of this study is to conduct a comprehensive empirical examination of the S\&P CNX Nifty index additions from 2000 to 2018 focusing on both the price and non-price effects and the explanations surrounding them.

The article proceeds as follows, the next section reviews the literature so far and develops the hypothesis. The third section details the data and methodology. The fourth section reports and discusses the results of the comprehensive empirical investigation. The fifth section concludes.

\section{Literature Review}

The prior research has evidenced significant price and non-price effects on the announcement day (AD) and the effective date of inclusion (ED). The explanations for those effects can be divided into two broad categories namely, information related theories and the demand related theories, based on the assumption of information content.

Shliefer (1986) and Harris and Gurel (1986) are the two pioneering studies which contributed to the basic research design, methodology and empirical techniques to analyse index addition and are used by the researchers till date. Shleifer (1986) analysed S\&P 500 additions for the 1976-1983 period and evidenced a permanent increase of $3 \%$ on the announcement day which persisted till at least 20 days after inclusion. Shleifer (1986) found support for the DSDC hypothesis which was later supported by the Lynch and Mendenhall (1997) and Wurgler and Zhuravskaya (2002). Harris and Gurel (1986) examined the S\&P 500 additions for the 1976-1983 period, evidenced a price increase to the tune of $3.13 \%$ post addition and documented a systematic reversal in support of price pressure hypothesis. Elliot et al. (2006) analysing the S\&P 500 additions and Mase (2002) studying FTSE 100 inclusions also found evidence in support of price pressure hypothesis.

In the recent studies on the index revisions, Hacibedel \& Bommel (2007), Daya et al. (2012) and Kamal (2014) found support for the information based theories. While Vespro (2006), 
Miller \& Ward (2015) and Wang et al. (2015) found support for the price pressure hypothesis, Cai and Houge (2008) and Fernandes and Mergulhao (2016) found support for the DSDC hypothesis. A few studies in the developed markets have evidenced declining index effects in the recent period, Soe and Dash (2008), Kamal (2014).

The studies focusing on Nifty index additions in the Indian market is quite limited. The studies could be classified into two categories based on whether they evidence permanent effects or not. The studies evidencing lack of permanent effects are Rahman and Rajib (2014) analysed the price and volume effects of companies included and excluded for the Nifty index during the 2008-2010 period, found evidence for short term effects for both the announcement day and inclusion day providing support to PPH. Kumar (2003) evidenced results similar to Rahman and Rajib (2014) findings. However, Parthasarathy, S. (2010), examined the Nifty index addition between 1999 and 2010, and evidenced permanent abnormal returns to the tune of $4.90 \%$. But the evidence for permanent abnormal volume was limited. This study found support for information related explanations. Chakrabarti et al (2005) studied additions to MSCI India Standard Index during the 1998-2000 period and evidenced permanent abnormal returns post announcement to the tune of $4.17 \%$ and found support for the information based theories.

The literature review brings out three important points; the empirical methodologies and varying explanation in such studies, the importance and continuing interest in index revision effects across the world and the conflicting evidence with regard to the price effects in the Indian Nifty additions. Though the sample was more or less similar, as all the Indian studies have predominantly studied the 1999-2009 period, the conflicting evidence and the varying explanations might be due to the choice of the methodology and the market index. This study intends to resolve this debate by conducting a comprehensive examination of the price and non-price effects in the $2000-2009$ period. This study also makes an important contribution by extending the literature to the hitherto unexplored recent period till 2018. To my best knowledge, no other study has examined the Nifty index additions in the recent $2000-2018$ period.

This study is very important in India for many reasons. The Indian equity market, one of the fastest growing economies in the world, will be the fifth largest in the world by the end of 2018 , in terms of both traded value and market capitalization. This study also addresses the lack of comprehensive single country studies in the emerging markets similar to Miller $\&$ Ward (2015) and Wang et al. (2015). The effects of unique regulatory environment, level of informational efficiency and liquidity can be understood by these studies.

Though, the price pressure hypothesis (predominantly due to the demand from index funds tracking the Nifty index) predicts temporary abnormal price and volume effects, both around $\mathrm{AD}$ and ED, the ED makes more sense as index funds will know the exact weights of the added stocks in the Nifty index around ED rather than AD. But if investors believe DSDC, imperfect substitutes and permanent abnormal returns, it makes sense for them to act at AD. Similarly, if investors perceive index addition as indicators of future improved performance or becoming more efficient in incorporating information into prices, then the abnormal price 
effects should occur around AD. In this study, the complete period (2000 -2018) is divided into two sub periods ${ }^{\mathrm{i}} ; 2000-2009$ and $2010-2018$.

If the Nifty index additions price effects are due to increase in expected cash flow due to certification or investor awareness. This study predicts an increase in the shareholding of retail investors and institutions (other than mutual funds), post addition. If the index addition increases liquidity, thereby reducing the discount rate, this study predicts an association between liquidity and the permanent abnormal returns around ADs for the complete period and the first sub period.

The Securities Exchange Board of India (SEBI), since 2000, had initiated steps ${ }^{2}$ to improve investor protection, disclosure norms and corporate governance, which has also contributed to the growth of both cash and mutual fund segment, especially from 2009 to 2018 . Consequently, information asymmetry might be reduced, well before the stock becomes eligible for Nifty index addition, especially in the later period. Therefore, this study predicts that the DSDC hypothesis might be the dominant explanation for the permanent abnormal returns around ADs in the second period.

\section{Data and Methods}

\subsection{NIFTY Information}

The National Stock Exchange (NSE) is the largest stock exchange in India and was ranked tenth in the world in terms of domestic market capitalization in $2017^{3}$. A total of 1938 companies are listed in the NSE with an annual turnover of approximately US\$ 1033 Billion in 2017-2018 and market capitalisation of approximately US\$ 2350 Billion as on March $2018^{4}$.AUM in Indian mutual fund industry increased fivefold from Rs 4173 billion between March 2009 and March 2018. The growth in equity category in the same period was nearly seven times. Further, midcap mutual funds have also grown exponentially in the same period. The Nifty 50 index (NIFTY) is the flagship index of the NSE tracking the portfolio of fifty large, liquid, blue chip companies and capturing approximately $63 \%$ of its equity market capitalization as on March, 2017.The Nifty is owned and managed by NSE Indices Ltd. The Nifty index constituents are selected on the basis of market capitalisation, liquidity and industry representation. The index is normally reviewed twice a year with a notice period of six weeks. The stocks are normally removed due to corporate actions like restructuring or when the free float market capitalisation of the companies eligible for inclusion is at least 1.5 times the free float market capitalisation of the smallest constituent in the index.

\subsection{Sample selection}

The sample period begins on April 2000 and ends on March 2018 to coincide with the start of index funds in India and chosen market index. The daily data from the NSE official website is used to calculate the return and volume of the added stocks and the market index. The data is adjusted for corporate actions like stock dividend and stock splits. During this sample period, 71 companies were added ${ }^{5}$ to the Nifty index and from this original sample of added stocks, a 'clean sample' is constructed. As in Chen et al (2003), Wurgler and Zhuvarskya (2002) and Hradzil (2007), only clean additions that did not result from spin-off, mergers \& 
acquisitions and name changes are considered reducing the sample to 60 . In two cases, the added stocks are excluded, as they did not have at least three clear days between the announcement date and inclusion date reducing the sample to 58. Apart from this, eight post-IPO stocks having less than one year trading history are also excluded to construct the 'clean' additions sample of 50 added stocks to avoid confounding effects. NSE normally makes the announcement four weeks before the actual inclusion day. The number of days between announcement and inclusion varies between 7 and 33 with a mean of approx 25 days. Appendix 1 lists the included companies with announcement and inclusion dates.

\subsection{Methodology}

This study uses an event study methodology of 'Brown and Warner' with two event dates for each sample; the announcement date of addition (AD) and effective date of addition (ED). As NSE normally announces the Nifty index revisions after trading hours, the following day or $\mathrm{AD}+1$ is the actual announcement day. The appropriate choice for market index is the CNX 500 index (a 500 stock portfolio), as it captures approximately $90 \%$ of NSE's equity market capitalization. This provides independence between the market portfolio and the index under examination as in Chakrabarti (2008). The choice of period of study (starting from 2000) is also due to the choice of CNX 500 as the market index and the daily data for this index is available only from June 1999.

\subsubsection{Cumulative Abnormal returns}

In order to examine the index addition effect, this cumulative abnormal return (CAR) is calculated around the two event dates namely, AD and ED. According to Kothari and Warmer (2007), the difficulty of dealing with statistical and econometric inferences in event study methodology might weaken the robustness and reliability of the results. Consequently, many alternative models of computing abnormal returns have been used in the extant literature. This study uses three abnormal return computational methods in this study.

The first method of computing the abnormal return is subtracting the CNX 500 index return from the stock return. The CAR is then the aggregated abnormal return(AR)over the estimation period as the CAR represents the buy and hold return which makes sense to the investors. The daily return is the log return using closing price at time $t$ and time $t-1$.

$$
\text { MCAR Abnormal Return } \mathrm{AR}_{\mathrm{it}}=\mathrm{R}_{\mathrm{it}}-\mathrm{R}_{\mathrm{mt}} \text {, }
$$

Where $\mathrm{R}_{\mathrm{it}}$ is the stock return and $\mathrm{R}_{\mathrm{mt}}$ is the CNX 500 index return on day ' $\mathrm{t}$ '.

The second model for calculating abnormal return in this study is the widely used OLS market model where the expected return is calculated as

$$
E\left[R_{i}\right]=\alpha_{i}+\beta_{i} E\left[R_{m}\right]
$$

Where, $\alpha_{i}$ and $\beta_{i}$ are the model parameters and $R_{m}$ is the CNX 500 return and the estimation window starts 130 days before and ends 10 days (approximately 120 trading days) before the index addition AD. The abnormal return is, 


$$
\text { OCARAbnormal Return } A R_{i t}=R_{i t}-\left(\hat{\alpha}_{i}+\hat{\beta}_{i} R_{m t}\right) \text {, }
$$

The abnormal return calculated by the OLS market model ${ }^{6}$ has two key methodological problems in the context of index revision studies. Lynch and Mendenhall(1987) point out that abnormal return might be biased downwards, as stocks added to the index are likely to have performed well just prior to the addition and using the daily data to estimate the model parameters may produce upwardly biased alpha estimates especially when aggregated over time. The second methodological problem is the possible shift in beta, post addition. Also, Jain (1987) shows that stocks perform better in the pre-addition period and estimation of pre event alphas and betas might vitiate the abnormal return estimates. In order to overcome this bias, the market model for 'high' alpha ${ }^{7}$ stocks in this study is again estimated using returns from 370 to 251 days prior to announcement day (approximately 120 trading days) in the spirit of Lynch and Mendenhall $(1987)^{8}$.

Thirdly, abnormal return is computed as the stock return minus the 'control sample' return (CCAR) as in Hradzil (2009). The stocks which are likely candidates for inclusion in the Nifty index based on market capitalization are candidates for control sample in this study. Normally, eligible stocks from another index, namely Nifty Junior index ${ }^{9}$ is added to the Nifty index and the deleted stocks usually get included in the Nifty Junior index. The top three stocks other than the added stocks will be the control sample since they had been considered for addition to Nifty index but are not included and will be the ideal candidates for the control sample. The ratio of control (eligible) stocks to added stocks is three to one.

\subsubsection{Abnormal volume}

The abnormal volume is calculated in the spirit of Harris and Gurel (1986)

$$
\text { Volume Ratio }(\mathrm{VR})=\left(\mathrm{V}_{\text {it }} / \mathrm{V}_{\mathrm{mt}}\right) \div\left(\mathrm{V}_{\mathrm{i}} / \mathrm{V}_{\mathrm{m}}\right)
$$

Where $\mathrm{V}_{\mathrm{it}}$ and $\mathrm{V}_{\mathrm{mt}}$ are the trading volumes of the stock and the total NSE respectively, and $\mathrm{V}_{\mathrm{i}}$ and $\mathrm{V}_{\mathrm{m}}$ are the average trading volumes of the stock and total NSE for the period AD-70 through AD-10. The daily VR is averaged across the various event windows and the volume ratio ${ }^{10}$ should have a value of 'one' under null hypothesis. In any event window, the volume ratio (VR) should be significantly greater than one.

\subsubsection{Liquidity ratio}

The liquidity measure employed in this study is the ratio of daily rupee volume of the stock to the absolute stock return as in Amihud (2002) ${ }^{11}$. This can be interpreted as the daily price response to one rupee of trading value and essentially capturing the price impact.

$$
\text { Liquidity Ratio (LR) }=\mathrm{VOL}_{\mathrm{it}} /\left|\mathrm{R}_{\mathrm{it}}\right| \div \mathrm{VOL}_{\mathrm{i}} /\left|\mathrm{R}_{\mathrm{i}}\right|
$$

Where $\mathrm{R}_{\mathrm{it}}$ is the daily stock return and $\mathrm{VOL}_{i t}$ is the daily rupee volume. ' $\mathrm{VOL}_{\mathrm{i}} /\left|\mathrm{R}_{\mathrm{i}}\right|$ 'is the average liquidity of the stock for the period $\mathrm{AD}-70$ through $\mathrm{AD}-10$. The liquidity ratio is averaged across the various event windows and if, in any event window, the average liquidity ratio is significantly greater than one, then it is said to be abnormal for that event window. 
Amihud (2002) has discussed the advantages of this measure and disadvantages of measures like rupee volume and turnover.

Lastly, prior researches have indicated that the methodological issue surrounding studies focusing on single event change like index addition could be exposed to biases in standard errors associated with date clustered event studies. This impact of the bias will be minimal for this study as on an average less than two stocks were added in the biannual revisions so far. Also, there are 30 unique ADs for the 50Nifty additions over the 18 year period.

\section{Results and Discussion:}

This section documents the Nifty index addition premia around the announcement date $(\mathrm{AD}+1)$ and the effective inclusion day (ED). In order to analyse the abnormal returns and disentangle the various explanations surrounding the price changes, this study focuses on the following event windows in the spirit of Lynch and Mendenhall (1987): anticipation window ( $\mathrm{AD}-10$ to $\mathrm{AD})$; announcement day $(\mathrm{AD}+1)$; run up window ( $\mathrm{AD}+2$ to $\mathrm{ED}-2)$; $\mathrm{ED}$ window (ED-1 to $\mathrm{ED})$; release window $(\mathrm{ED}+1$ to $\mathrm{ED}+3)$; long term window $(\mathrm{AD}+1$ to $\mathrm{AD}+40$ or $\mathrm{AD} 40)$ and long term window $(\mathrm{AD}+1$ to $\mathrm{AD}+60$ or $\mathrm{AD} 60)$. The $\mathrm{CAR}$ is considered permanent in this study, if it is permanent for at least 40 days from ADin order to avoid the noise added by other events and news.

\subsection{Complete Period - 2000-2018}

Table 1 reports the mean, median and the fraction of added stocks with positive CAR for all the chosen event windows for the clean sample for the Nifty index additions for the 'complete' period.For the complete period 2000- 2018, Table 1 reports a significant AD+1 abnormal return of $1.49 \%$ that persists not only for 40 days $(3.50 \%$, P-value $<0.1)$ but also for 60 days $(4.19 \%, \mathrm{P}$-value $<0.05)$ from $\mathrm{AD}+1$. The evidenced significant announcement day abnormal return is robust to alternate measures of abnormal return computational methods. Consistent with the findings of Chakrabarti et al. (2005) and Hacibedel \& Bommel (2007), this study evidenced smaller index addition effect in India compared to the developed markets. The evidenced $\mathrm{AD}+1$ return of $1.49 \%$ is comparatively smaller than that of the developed markets. Also, the $\mathrm{AD}+1$ abnormal return, for the added firms, is significantly larger than for the chosen control firms.

The next important result, from Table 1, is the abnormal return around the actual inclusion day return or effective day (ED). The added firms experience a statistically significant ED window MCAR of $1.67 \%$ for the complete period. Table 1 reports a partial price reversal to the tune of $-1.5 \%$ suggesting more tests to examine the price pressure around ED.

Table 2 and Table 3 present the abnormal volume (VR) results around AD and ED respectively. Even though, the mean VR is greater than one for most of the days around AD and the event windows for the complete period, the median along with the fraction of stocks with VR $>1$ suggest that the high volume outliers have skewed the results. The VR is significant only if the statistical significance suggested by the parametric t-test is confirmed by the non-parametric Wilcoxon signed rank test. It is seen that the mean VR is not significantly greater than one at any reasonable level of significance for any event window 


\section{Macrothink}

ED and pressure release window for the complete period. The significant price effects without accompanying volume increase in the Nifty index addition are different from those other studies in the developed markets Beneish and Whaley (1996),Hegde and McDermott (1988), Chen et al. (2003) and Hradzil (2009).

\subsection{Sub Period Results}

Table 1 reports a significant $\mathrm{AD}+1$ window $^{12}$ abnormal return of $2.32 \%$ that persists not only for 40 days $(5.06 \%$, P-value $<0.05)$ but also for 60 days $(6.28 \%$, P-value $<0.05)$ from $\mathrm{AD}+1$ for the first period. This result contradicts earlier studies in the Indian stock market which have evidenced temporary abnormal returns, that too around ED only. The OCAR and the adjusted OCAR results for AD40 \& AD60 permanent abnormal return for first period clearly show the dampening effect of high alpha stocks. These results suggest that the choice of market model for abnormal returns, choice of market index and the estimation period close to $\mathrm{AD}$ might be the reasons for the lack of permanent abnormal returns evidenced by earlier studies on Nifty index additions for the same period.

For the second period, Table 1 reports a $\mathrm{AD}+1$ abnormal return of $1.24 \%$ that persists not only for 40 days $(2.18 \%)$ but also for 60 days $(2.43 \%)$ from $\mathrm{AD}+1$.Though, the index effect appears to be declining in the recent period similar to some studies in the developed markets, the AD40 and AD60 permanent CCARs in the second period are statistically significant at $2.57 \%$ and $3.64 \%$ respectively. The complete period and the sub period results are robust to alternate abnormal return calculations. Overall, the results evidence significant permanent abnormal returns following index additions for the first period and second period. 
Table 1. Long Window statistics for the daily abnormal returns using multiple calculation methodology for the clean sample added to Nifty index during the complete period, April 2000 - March 2018, sub period 1 (2000 - 2009) and sub period 2 (2010-2018).

\begin{tabular}{|c|c|c|c|c|c|c|c|c|c|c|}
\hline \multirow[t]{2}{*}{ Windows } & & \multicolumn{2}{|c|}{ Complete Period } & \multirow{2}{*}{$\begin{array}{l}\mathbf{N}=\mathbf{5 0} \\
\text { OCAR }\end{array}$} & \multicolumn{2}{|c|}{ I Period } & $\mathbf{N}=\mathbf{2 3}$ & \multicolumn{2}{|c|}{ II Period } & \multirow{3}{*}{$\begin{array}{r}\mathbf{N}=\mathbf{2 7} \\
\text { OCAR }\end{array}$} \\
\hline & & MCAR & CCAR & & MCAR & CCAR & OCAR & MCAR & CCAR & \\
\hline \multicolumn{10}{|l|}{ CAR in $\%$} & \\
\hline \multicolumn{11}{|l|}{ Anticipation } \\
\hline Window & Mean & $-0.70 \%$ & $-1.21 \%$ & $-0.74 \%$ & $-0.90 \%$ & $-1.14 \%$ & $-0.94 \%$ & $-0.51 \%$ & $-1.26 \%$ & $0.57 \%$ \\
\hline \multirow[t]{2}{*}{$\mathrm{AD}-10 ; \mathrm{AD}$} & Median & $-0.30 \%$ & $-1.14 \%$ & $-0.05 \%$ & $-0.40 \%$ & $-1.76 \%$ & $-0.58 \%$ & $0.10 \%$ & $-0.90 \%$ & $0.02 \%$ \\
\hline & $\mathrm{CAR}>0$ & $48 \%$ & $40 \%$ & $48 \%$ & $43 \%$ & 48 & $43 \%$ & $52 \%$ & $43 \%$ & $52 \%$ \\
\hline \multicolumn{11}{|l|}{$\mathrm{AD}$ window } \\
\hline \multirow[t]{3}{*}{$\mathrm{AD}+1$} & Mean & $1.49 \% * *$ & $1.94 \% * *$ & $1.25 \% * *$ & $2.32 \% * *$ & $3.32 \% * *$ & $1.96 \% * *$ & $1.24 \% * *$ & $1.19 \%$ ** & $1.32 \% * *$ \\
\hline & Median & $2.30 \%$ & $2.13 \%$ & $2.15 \%$ & $2.67 \%$ & $2.81 \%$ & $3.33 \%$ & 1.53 & $1.76 \%$ & 1.25 \\
\hline & $\mathrm{CAR}>0$ & $66 \%$ & $66 \%$ & $62 \%$ & $78 \%$ & $74 \%$ & $70 \%$ & $78 \%$ & $63 \%$ & $81 \%$ \\
\hline Run up window & Mean & $2.30 \% *$ & $2.69 \%$ * & $2.83 \% * *$ & $3.66 \% *$ & $3.41 \%$ & $4.37 \% *$ & $1.21 \%$ & $2.10 \%$ & $1.52 \%$ \\
\hline \multirow[t]{2}{*}{$\mathrm{AD}+2 ; \mathrm{ED}-2$} & Median & $3.40 \%$ & $1.43 \%$ & $1.58 \%$ & $5.12 \%$ & $5.23 \%$ & $2.79 \%$ & $1.90 \%$ & $0.90 \%$ & $0.61 \%$ \\
\hline & $\mathrm{CAR}>0$ & $62 \%$ & $54 \%$ & $58 \%$ & $74 \%$ & $61 \%$ & $65 \%$ & $52 \%$ & $52 \%$ & $52 \%$ \\
\hline ED Window & Mean & $1.67 \% * *$ & $1.63 \% * *$ & $1.42 \% * *$ & $1.81 \% * *$ & $1.72 \% *$ & $1.22 \% * *$ & $1.56 \% * *$ & $1.55 \%$ ** & $1.6 \% * *$ \\
\hline \multirow[t]{2}{*}{ ED-1; ED } & Median & $1.57 \%$ & $1.34 \%$ & $1.12 \%$ & $2.10 \%$ & $1.30 \%$ & $1.10 \%$ & $1.24 \%$ & $1.34 \%$ & $1.25 \%$ \\
\hline & $\mathrm{CAR}>0$ & $70 \%$ & $76 \%$ & $68 \%$ & $70 \%$ & $70 \%$ & $61 \%$ & $70 \%$ & $81 \%$ & $74 \%$ \\
\hline \multicolumn{11}{|l|}{ Pressure } \\
\hline Release & Mean & $-1.50 \% * *$ & $-2.02 \% * *$ & $-1.61 \% * *$ & $-2.03 \% *$ & $-3.03 \% * *$ & $-2.49 \%$ & $-0.78 \%$ & $-1.11 \%$ & $-0.85 \%$ \\
\hline \multirow[t]{2}{*}{$\mathrm{ED}+1 ; \mathrm{ED}+3$} & Median & $-1.49 \%$ & $-1.04 \%$ & $-1.16 \%$ & $-2.22 \%$ & $-2.82 \%$ & $-2.17 \%$ & $-0.93 \%$ & $-1.10 \%$ & $-0.91 \%$ \\
\hline & $\mathrm{CAR}>0$ & $32 \%$ & $24 \%$ & $28 \%$ & $26 \%$ & $17 \%$ & $22 \%$ & $37 \%$ & $30 \%$ & $33 \%$ \\
\hline \multicolumn{11}{|l|}{ Permanent AD } \\
\hline 40 & Mean & $3.50 \% *$ & $3.32 \% *$ & $3.96 \% *$ & $5.06 \% * *$ & $3.53 \%$ & $5.62 \% *$ & $2.18 \%$ & $3.06 \% *$ & $2.57 \% *$ \\
\hline \multirow[t]{2}{*}{$\mathrm{AD}+1 ; \mathrm{AD}+40$} & Median & $3.10 \%$ & $1.62 \%$ & $4.72 \%$ & $3.98 \%$ & $1.02 \%$ & $8.09 \%$ & $2.12 \%$ & $4.19 \%$ & $3.20 \%$ \\
\hline & $\mathrm{CAR}>0$ & $60 \%$ & $56 \%$ & $60 \%$ & $65 \%$ & $54 \%$ & $61 \%$ & $56 \%$ & $56 \%$ & $59 \%$ \\
\hline \multicolumn{11}{|l|}{ Permanent AD } \\
\hline 60 & Mean & $4.19 \% * *$ & $4.23 \% *$ & $4.49 \%$ & $6.28 \% * *$ & $5.09 \% *$ & $5.51 \%$ & $2.43 \%$ & $3.41 \%$ * & $3.64 \% *$ \\
\hline \multirow[t]{2}{*}{$\mathrm{AD}+1 ; \mathrm{AD}+60$} & Median & $4.12 \%$ & $2.94 \%$ & $2.73 \%$ & $5.19 \%$ & $2.24 \%$ & $5.27 \%$ & $3.86 \%$ & $5.31 \%$ & $2.54 \%$ \\
\hline & $\mathrm{CAR}>0$ & $60 \%$ & $58 \%$ & $60 \%$ & $65 \%$ & $54 \%$ & $65 \%$ & $56 \%$ & $63 \%$ & $59 \%$ \\
\hline
\end{tabular}

This table reports the long window statistics for the daily abnormal return for the clean sample for the complete period (2000-2018), first period (2000 - 2009) and second period (2010 - 2018). Using the standard event methodology, the market adjusted (MCAR): 'Adjusted' market model adjusted (OCAR); control sample adjusted (CCAR), buy and hold, CARs using daily returns from the NSE, India official website (equation 1,2 and 3). The market return is represented by the CNX 500 index return. The control sample are the other firms which satisfy all the addition criteria, however were not added. AD-10:AD CAR represents CAR from AD-10 to AD. Permanent AD 40 indicates $\mathrm{CAR}$ from $\mathrm{AD}+1$ to $\mathrm{AD}+40$. The mean and median $\mathrm{CAR}$ are reported. $\mathrm{CAR}>0$ represents the fraction of stocks for which the $\mathrm{CAR}$ is positive. values are returns in percentages and **, * represents significance ( $\mathrm{t}$-test) at $5 \%$ level and $10 \%$ level respectively.

The complete period unadjusted AD40 \& AD60 OCAR are 2.86\% and 2.85\% respectively. The first period unadjusted AD40 \& AD60 OCAR are $4.39 \%$ and $3.73 \%$ respectively. The second period unadjusted AD40 \& AD60 OCAR are $1.57 \%$ and $2.10 \%$ respectively. This table reports 
the long window statistics for the daily abnormal return for the clean sample for the complete period (2000-2018), first period (2000 - 2009) and second period (2010 - 2018). Using the standard event methodology, the market adjusted (MCAR): 'Adjusted' market model adjusted (OCAR); control sample adjusted (CCAR), buy and hold, CARs using daily returns from the NSE, India official website (equation 1,2 and 3). The market return is represented by the CNX 500 index return. The control sample are the other firms which satisfy all the addition criteria, however were not added. AD-10:AD CAR represents CAR from AD-10 to AD. Permanent AD 40 indicates $\mathrm{CAR}$ from AD+1 to AD+40.The mean and median CAR are reported. CAR $>0$ represents the fraction of stocks for which the CAR is positive. values are returns in percentages and $* *, *$ represents significance $(\mathrm{t}-$ test $)$ at $5 \%$ level and $10 \%$ level respectively.

The complete period unadjusted AD40 \& AD60 OCAR are 2.86\% and 2.85\% respectively. The first period unadjusted AD40 \& AD60 OCAR are $4.39 \%$ and $3.73 \%$ respectively. The second period unadjusted AD40 \& AD60 OCAR are $1.57 \%$ and $2.10 \%$ respectively.

Table 2. Daily Abnormal Volume (VR) for the Nifty index additions during the 2000-2018 period

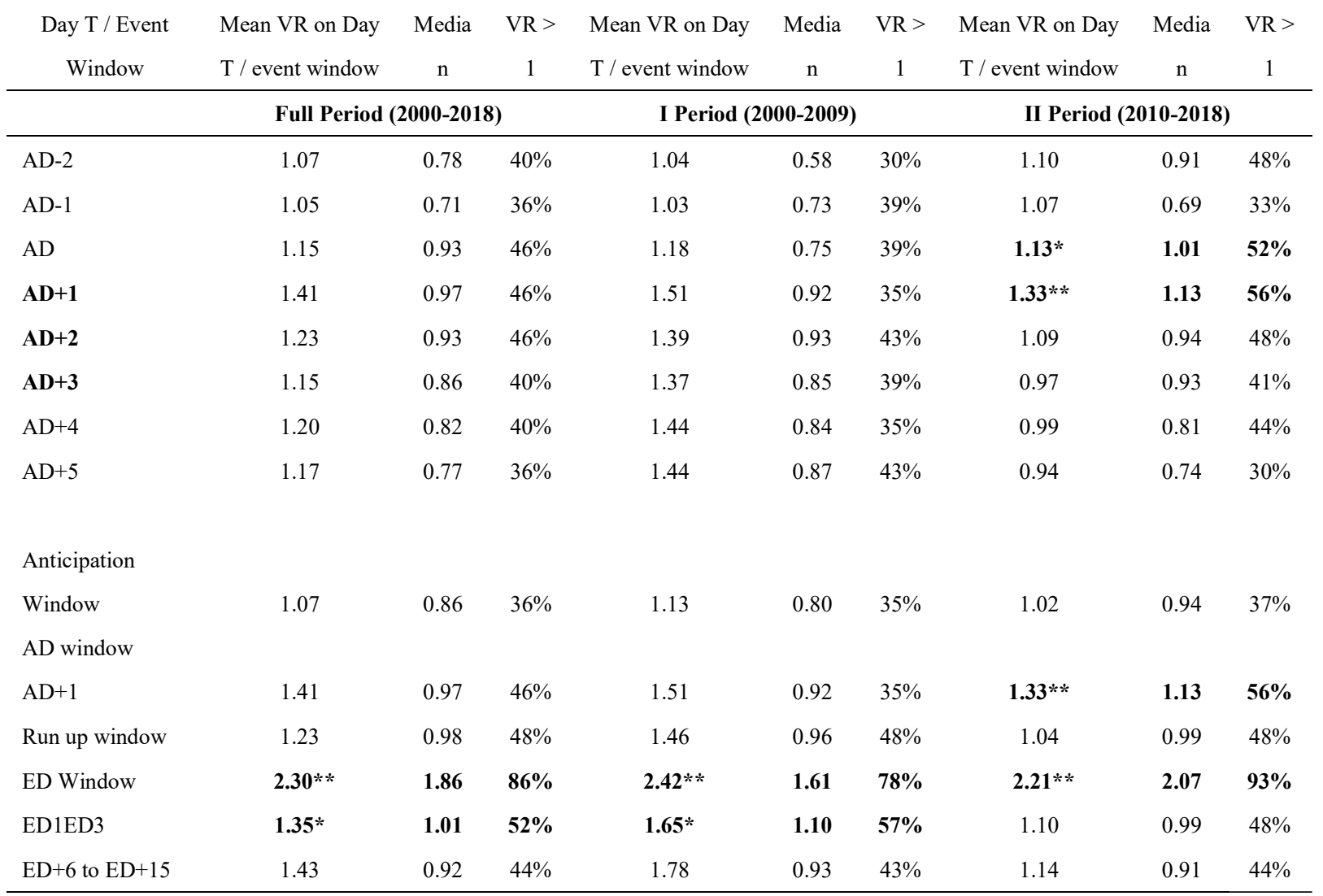

The samples are described in sec 3.2. The Volume Ratio (VR) calculation is explained in sec 3.3.2. . The VR is significant only if the statistical significance suggested by the parametric t-test is confirmed by the non-parametric Wilcoxon signed rank test.

**, * represents significance ( $\mathrm{t}$-test) at $5 \%$ level and $10 \%$ level respectively. 
Table 3. Mean CAR from ED+1 to Day $\mathrm{T}$ and the Mean AR on day $\mathrm{T}$ for the 38 stocks added to Nifty index between 1999-2018 and for which ED abnormal return is greater than zero.

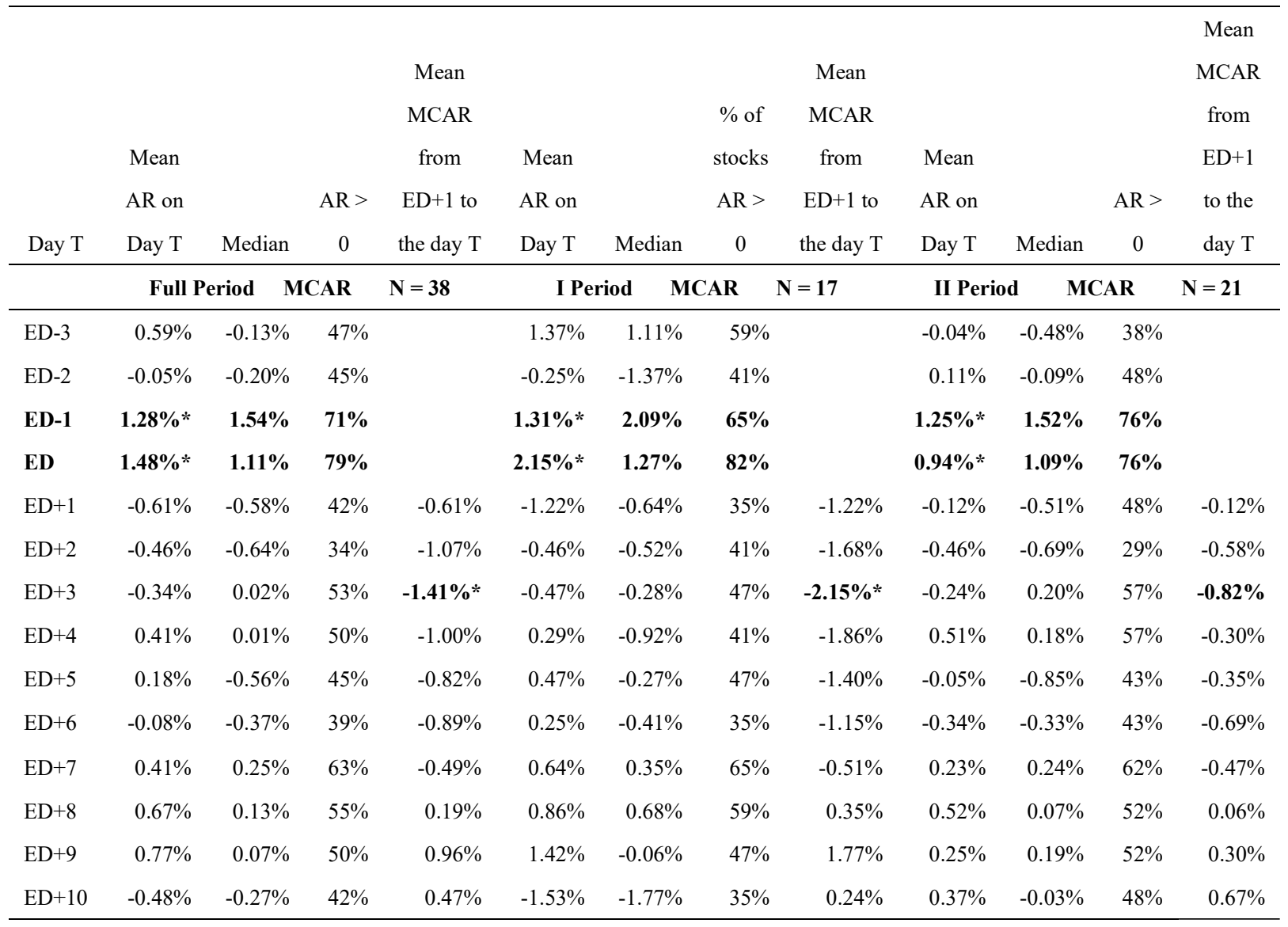

This table reports the Mean CAR from ED +1 to Day T and the Mean AR on day T for the 38 stocks added to Nifty index for the full period (2000-2018), first period (2000 - 2009) and second period (2010 - 2018) and for which ED abnormal return is greater than zero. AR $>0$ represents the fraction of stocks for which the AR is positive. Values are returns in percentages. * represents significance (t -test) at $5 \%$ level respectively. The II period $\mathrm{ED}+1$ to $\mathrm{ED}+3 \mathrm{CAR}$ is significant at $10 \%$ level.

Table 2 and Table 3 present the abnormal volume (VR) results around AD and ED respectively for both the sub periods. The mean VR is not significantly greater than one at any reasonable level of significance for any event window except for the ED and pressure release window for the first sub period. However, the AD+1 VR is significant for the second period. Overall, there is no evidence of significant permanent abnormal volume for the complete period, first sub period and second sub period. The significant price effects without accompanying volume increase in the Nifty index addition are different from those of other studies in the developed markets Beneish and Whaley (1996), Hegde and McDermott (1988), Chen et al. (2003) and Hradzil (2009).

\subsection{Nifty index reconstitutions in the context of prior research}

This study examines the prior explanations in the literature in the context of the Nifty index reconstitutions. 


\subsubsection{Tests for DSDC hypothesis}

The evidence of abnormal volume effects so far, is not consistent with the DSDC hypothesis in the complete period and first sub period. According to Beneish \& Whaley (1986), price and volume increase around $\mathrm{AD}$ is evidence of short term investors front running the index funds indicating the possibility of downward sloping demand curves. The evidence of abnormal returns and abnormal volume in second sub period is so far consistent with the previous findings for DSDC hypothesis

Shliefer (1986) contends that a significant positive slope in the cross sectional regression between abnormal AD return and volume is consistent with DSDC hypothesis. In order to complete the DSDC analysis and to delineate which variables explain the index addition premia, This study uses Shliefer (1986) cross sectional regression on various intervals around $\mathrm{AD}$ namely, $\mathrm{AD}+1 ; \mathrm{AD}+1$ to $\mathrm{AD}+2 ; \mathrm{AD}+1$ to $\mathrm{AD}+3$. Table $5^{13}$, Panel $\mathrm{A}$ reports only the $\mathrm{AD}+1$ to $\mathrm{AD}+2$ results $^{14}$.

$$
\mathrm{AD} 2 \text { window } \mathrm{CAR}=\alpha+\psi * \mathrm{AD} 2 \mathrm{ABVOL}_{\mathrm{i}}+\varepsilon_{\text {it }}
$$

Where, $\mathrm{AD} 2$ window $\mathrm{CAR}$ is the $\mathrm{AD}+1$ to $\mathrm{AD}+2 \mathrm{CAR}, \mathrm{AD} 2 \mathrm{ABVOL}$ is the mean $(\mathrm{AD}+1$ and $A D+2)$ VR. The results show that the slope estimate was negative for the complete period and first period and positive at $10 \%$ level of significance for second period. Further, Shliefer (1986) asserts that due to standard errors, the slope coefficient may be biased towards zero and suggested introducing usual volume USVOL independently in the regression. A significantly positive abnormal volume coefficient and significantly negative usual volume slope coefficient is consistent with DSDC hypothesis.

$$
\mathrm{AD} 2 \text { window } \mathrm{CAR}=\alpha+\psi * \mathrm{AD}^{2} \mathrm{ABVOL}_{\mathrm{i}}+\mu * \mathrm{USVOL}_{\mathrm{i}}+\varepsilon_{\mathrm{it}}
$$

Where, USVOL is usual volume and is the mean VR from AD-10 to AD- $5^{15}$.

The results, reported in Table 4 Panel A, show that the sign of the coefficients are of the expected sign for both the ABVOL and USVOL in the complete period and the two sub periods. However, though the slope coefficient of USVOL is negative and statistically significant at $10 \%$ level in the complete period, the slope coefficient of ABVOL is not significant at any level of significance suggesting weak support for DSDC hypothesis. The first period regression result coefficients are of expected sign but not statistically significant. In the second period, the coefficient of ABVOL is positive and significant at 5\% level. The slope coefficient of USVOL is negative and significant at 5\% level. The volume results along with these results are consistent with downward sloping curves in the second period. However, the results of the complete period and first period are not consistent with the DSDC hypothesis.

\subsubsection{Tests for price pressure hypothesis}

The price pressure hypothesis also posits a downward sloping demand curve, albeit only in the short run. Also, the inclusion or effective day abnormal return is expected to be positive due to indexing. Hence, I have included only the stocks with positive ED window CAR as 
this more appropriate as the price pressure hypothesis postulates complete reversion once the excess demand is satisfied.

Table 3 presents the mean daily return around ED along with the CAR from ED +1 to Day $\mathrm{T}$ till ED +10 . The ED window CAR for the complete period is $2.72 \%$ with a maximum cumulative reversal in ED+3 of $-1.41 \%$. The ED window CAR for the first period and sub period 2 are $3.46 \%$ and $2.61 \%$ respectively. The maximum cumulative reversals happen atED +3 in both the sub periods at -2.15 and $-0.82 \%$ respectively. The price reversal appears partial and does not support the price pressure hypothesis.

If the price reversal is only due to short term price pressure, then the magnitude of reversal should be inversely proportional to ED window CAR. I regress the pressure release window $\mathrm{ED}+1$ to ED+3 CAR with the ED window CAR similar to Elliot et al. (2006)

$$
\text { Pressure release window CAR }=\alpha_{0}+\alpha_{1} \text { ED window CAR }+\varepsilon_{\text {it }}
$$

If the cross sectional variation in the pressure release window is correlated with the initial ED window price shock, then the slope coefficient should be closer to negative one. Table 4, Panel $\mathrm{C}$ reports the results of the regression and though the slope coefficients are negative, they are neither significant not closer to negative one for the complete period, first period and second period. Therefore, it seems reasonable to conclude that the evidence in support of price pressure hypothesis is limited at best.

\subsubsection{Test for Investor Awareness and Certification}

The assessment of investor awareness and certification is difficult in the absence of direct measures. As in Chen et al. (2003), I rely on proxies like percentage in shareholding ${ }^{16}$ of Mutual Funds and non-Mutual funds.

The percentage of shareholding by mutual funds and others before announcement of the index addition is compared with the percentage of shareholding after the effective date of addition. The percentage of shareholding data before $\mathrm{AD}$ is obtained from the quarter immediately preceding the AD. The percentage of shareholding data after the effective date is obtained is obtained six months after the effective date similar to Chen et al. (2003). The Mean \% change in Mutual funds (MF) holding and the Mean \% change in Non - MFs holding before and after the Nifty index additions are reported in Table 5 Panel D. 
Table 4. Univariate and regression results - Nifty Index Additions

\begin{tabular}{|c|c|c|c|c|c|c|}
\hline \multicolumn{7}{|c|}{$\begin{array}{c}\text { Panel A: DSDC Hypothesis } \\
\text { Dependent variable - AD2 Abnormal return }\end{array}$} \\
\hline \multicolumn{3}{|c|}{ Complete period $\mathrm{N}=50$} & \multirow{2}{*}{$\frac{\text { I Period }}{\text { Reg } 1}$} & \multirow{2}{*}{$\begin{array}{r}\mathrm{N}=23 \\
\mathrm{Reg} 2\end{array}$} & \multicolumn{2}{|c|}{ II Period N $=27$} \\
\hline & Reg 1 & Reg2 & & & Reg 1 & Reg2 \\
\hline $\mathrm{C}$ & 0.016 & $0.025 * *$ & $0.028^{*}$ & $0.031 *$ & -0.011 & 0.008 \\
\hline Prob & $(0.12)$ & $(0.04)$ & $(0.08)$ & $(0.09)$ & $(0.39)$ & $(0.55)$ \\
\hline AD ABVOL & -0.003 & 0.003 & -0.009 & -0.006 & $0.016^{*}$ & $0.024 * *$ \\
\hline Prob & $(0.58)$ & $(0.49)$ & $(0.26)$ & $(0.57)$ & $(0.09)$ & $(0.01)$ \\
\hline USVOL & & $-0.018 *$ & & -0.008 & & $-0.030 * *$ \\
\hline Prob & & $(0.09)$ & & $(0.64)$ & & $(0.02)$ \\
\hline $\mathrm{R}$ sq & 0.02 & 0.064 & 0.059 & 0.069 & 0.11 & 0.303 \\
\hline
\end{tabular}

Panel B: Liquidity Hypothesis

Dependent variable - AD40 Abnormal return

\begin{tabular}{lcccccc}
\multicolumn{2}{c}{ Complete period N $=50$} & I Period & $\mathrm{N}=23$ & \multicolumn{2}{c}{ II Period N $=27$} \\
\hline C & 0.001 & -0.019 & 0.018 & -0.026 & -0.018 & -0.011 \\
Prob & $(0.98)$ & $(0.63)$ & $(0.80)$ & $(0.68)$ & $(0.77)$ & $(0.12)$ \\
AD40 ABVOL & 0.027 & 0.01 & 0.022 & -0.007 & 0.035 & 0.046 \\
Prob & $(0.38)$ & $(0.72)$ & $(0.56)$ & $(0.85)$ & $(0.51)$ & $(0.15)$ \\
AD40 ABLIQ & & $0.023^{* *}$ & & $0.041^{* *}$ & & -0.012 \\
Prob & & $(0.03)$ & & $(0.02)$ & & $(0.34)$ \\
R sq & 0.021 & 0.11 & 0.016 & 0.273 & 0.018 & 0.055 \\
\hline
\end{tabular}

Panel C: Price Pressure hypothesis

Dependent variable - ED release window

\begin{tabular}{|c|c|c|c|c|c|}
\hline \multicolumn{2}{|c|}{ Complete period $\quad \mathrm{N}=38$} & \multirow{2}{*}{$\begin{array}{r}\text { I Period } \\
-0.018\end{array}$} & $\mathrm{~N}=18$ & \multicolumn{2}{|c|}{ II Period $\mathrm{N}=20$} \\
\hline $\mathrm{C}$ & -0.007 & & & \multicolumn{2}{|l|}{-0.001} \\
\hline Prob & $(0.39)$ & \multicolumn{2}{|l|}{$(0.28)$} & \multicolumn{2}{|l|}{$(0.87)$} \\
\hline \multirow[t]{2}{*}{ ED WINDOW } & -0.257 & \multicolumn{2}{|l|}{-0.097} & \multicolumn{2}{|l|}{-0.314} \\
\hline & $(0.26)$ & \multicolumn{2}{|l|}{$(0.81)$} & \multicolumn{2}{|l|}{$(0.28)$} \\
\hline $\mathrm{R} \mathrm{sq}$ & 0.035 & 0.004 & & \multicolumn{2}{|l|}{0.06} \\
\hline \multicolumn{6}{|c|}{ Panel D: Investor Awareness and certification hypothesis } \\
\hline & & \multicolumn{2}{|c|}{ Complete Period $\mathrm{N}=50$} & $\begin{array}{c}\text { I Period } \\
\mathrm{N}=23\end{array}$ & $\begin{array}{c}\text { II Period } \\
\mathrm{N}=27\end{array}$ \\
\hline \multirow{2}{*}{\multicolumn{2}{|c|}{ Mean $\%$ change in MFs holding }} & Mean & $-0.12 \%$ & $-0.53 \% *$ & $0.22 \%$ \\
\hline & & Median & $0.04 \%$ & $-0.44 \%$ & $0.20 \%$ \\
\hline \multicolumn{3}{|c|}{$\%$ change $>0$} & $51.00 \%$ & $41 \%$ & $59.00 \%$ \\
\hline \multirow{2}{*}{\multicolumn{2}{|c|}{ Mean $\%$ change in Non - MFs holding }} & Mean & $0.32 \% *$ & $0.89 \% *$ & $-0.16 \%$ \\
\hline & & Median & $0.17 \%$ & $0.88 \%$ & $-0.11 \%$ \\
\hline \multicolumn{3}{|c|}{$\%$ change $>0$} & $61 \%$ & $73 \%$ & $31 \%$ \\
\hline
\end{tabular}


The Panel A relates the abnormal returns around AD with the abnormal volume and usual volume for the complete period and first period and second period. The specified equations are $\quad \mathrm{AD} 2$ window $\mathrm{CAR}=\alpha+\psi * \mathrm{AD} 2 \mathrm{ABVOL}+\varepsilon_{\text {it }}$

\section{$\mathrm{AD} 2$ window $\mathrm{CAR}=\alpha+\psi * \mathrm{AD} 2 \mathrm{ABVOL}+\mu * \mathrm{USVOL}+\varepsilon$ it.}

The dependent variable is $\mathrm{AD}+1$ to $\mathrm{AD}+2 \mathrm{CAR}$. Abnormal volume isthe average VR for $\mathrm{AD}+1$ and $\mathrm{AD}+2$. The usual volume is the mean $\mathrm{VR}$ from $\mathrm{AD}-10$ to $\mathrm{AD}-5$. The statistic and associated $\mathrm{p}$-values are given. $* *, *$ represents significance ( $\mathrm{t}$-test) at $5 \%$ level and $10 \%$ level respectively.

The Panel B relates the abnormal return with abnormal volume and abnormal liquidity for the complete period and first period and second period. The specified equation is $\mathrm{AD} 40 \mathrm{CAR}=\alpha_{0}+\alpha_{1} \mathrm{ABVOLi}+\alpha_{2} \mathrm{ABLIQi}+\varepsilon_{\text {it }}$

CAR $A D+1$ to $A D+40(A D 40)$ is the dependent variable. AD40 ABVOL is the average $\mathrm{VR}$ from $\mathrm{AD}+1$ to $\mathrm{AD}+40$. The ABLIQ is the average $\mathrm{LR}$ from $\mathrm{AD}+1$ to $\mathrm{AD}+40$. The statistic and associated p-values are given. ${ }^{*}, *$ represents significance $(\mathrm{t}-$-test) at $5 \%$ level and $10 \%$ level respectively.

The Panel C relates the ED release window CAR with the ED window car for added stocks with positive ED abnormal return. The specified equation is

Pressure release window CAR $=\alpha_{0}+\alpha_{1}$ ED window CAR $+\varepsilon_{\text {it }}$.

ED release window CAR is ED+1 to ED+3 CAR. ED window CAR is ED-1 to ED CAR. The statistic and associated $\mathrm{p}$-values are reported. $* *, *$ represents significance $(\mathrm{t}$-test) at $5 \%$ level and $10 \%$ level respectively.

Panel D compares the percentage of shareholding around the Nifty index additions. The percentage of share holding data before $\mathrm{AD}$ is obtained from the quarter immediately preceding the $\mathrm{AD}$. The percentage of share holding data after the effective date is obtained is obtained six months after the effective date. ${ }^{* *}, *$ represents significance $(\mathrm{t}-\mathrm{test})$ at $5 \%$ level and $10 \%$ level respectively.

The non-MFs holding includes banks, insurance companies, retail investors and non-resident Indians. Table 4 Panel D reports the paired changes where the change for each form is calculated before calculating the mean and median as in Chen et al. (2003). The mean percentage change in non-MF shareholding increases by a statistically significant $0.32 \%$; increases by a statistically significant $0.89 \%$ in the first period; and reduces by $0.16 \%$ in the second period. The change in the percentage of non-MF holding is large and statistically significant for the complete period and the first period. 
When the index funds buys large amount of stock following index additions, pressure is exerted on the non-MFs in general and non-institutional investors in particular in the direction of reduction in the shareholding in the absence of opposite forces like certification or investor awareness Chen et al. (2003). Even though, index funds have grown compared to the first period, the substantial increase in percentage change in non-MF shareholding supports the investor awareness and certification hypothesis in the complete period and the first period.

The mean percentage change in MF shareholding falls by $0.12 \%$ in the complete period; falls by a statistically significant $0.53 \%$ in the first period and increases by $0.22 \%$ in the second period. The increase in the percentage of MF shareholding and decrease in the percentage of non-MF shareholding ${ }^{17}$ in the second period also corroborate earlier evidence suggesting that the DSDC hypothesis might explain the price effects in that sub period.

\subsubsection{Tests for liquidity hypothesis}

Chen et al (2003) contend that liquidity can improve without information production provided there is an increase in the trading volume. The reason being the increase in trading volume normally lowers the cost of trading by reducing the inventory cost of market makers. On the other hand, indexing could also reduce liquidity. The results in Table 2 suggest that there is no significant abnormal volume in any chosen event windows, except ED window for both the complete period and first period. Also, there is a significant volume increase around $\mathrm{AD}$, only for the second period. Consequently, if there is an increased interest for the added stocks, liquidity increase could be due to increased information production by analysts and others.

This study specifies a regression model with the permanent window CAR as the dependent variable and the regressors are proxies for liquidity (Liquidity ratio) and volume (Volume ratio). The model is similar in spirit to Beneish and Gardner (1995) and Gregoriou et al. (2006).

$$
\mathrm{AD} 40 \mathrm{CAR}=\alpha_{0}+\alpha_{1} \mathrm{ABVOL}_{\mathrm{i}}+\alpha_{2} \mathrm{ABLIQ}_{\mathrm{i}}+\varepsilon_{\text {it }}
$$

Where, AD40 CAR is the MCAR from $\mathrm{AD}+1$ to $\mathrm{AD}+40$, ABVOL is the mean $\mathrm{VR}$ and ABLIQ is the mean LR for the same period.

Table 4, Panel B presents the results of the cross sectional regression. The variable ABVOL, though positive, is not significant for the complete period, first period and second period. The variable ABLIQ is positive and statistically significant for the complete period and first sub period. Similar results were evidenced with AD60 as the dependent variable. These results corroborate the earlier finding that information related effects might explain the permanent abnormal return in the complete period and first period. The variable ABLIQ is negative and not significant in the second sub period suggesting that the information related effects might not explain the permanent abnormal return in second sub period. The results for the first period is similar to that of Hacibedel \& Von Bommel (2007) that index changes in emerging markets are not information free events. However, the second period results are similar to that of the mature markets. 
The evidence suggesting downward sloping demand curve as the explanation for the permanent abnormal returns in the second period is not consistent with efficient market hypothesis $(\mathrm{EMH})$ in the Indian stock market which relies on arbitrage and price takers in competitive market. Further, the basic assumption in finance theory, that the price of the stock is determined only by the information about future cash flows and appropriate discount rate, is not consistent with the downward sloping curve. Also, the slow multi day adjustment to Index addition announcement is not consistent with market efficiency in the Indian stock market.

\section{Conclusion}

This paper documents the price and non-price effects of the additions to Nifty index during 2000-2018. The stocks added to Nifty index experience a significant permanent increase in abnormal return subsequent to announcement and inclusion similar to the effect seen in the developed markets. But the evidence of permanent abnormal volume is limited, unlike the developed markets, as abnormal volume is evidenced only around announcement date and inclusion date. There is clear evidence that the Nifty index addition during the $2000-2018$ is associated with permanent abnormal return in the complete and the sub periods. The statistically and economically significant permanent abnormal returns in the complete period and first period contradict some of the earlier studies on Nifty index addition which evidenced temporary abnormal returns around the actual inclusion day.

Among the four different views in the extant literature - information effect, liquidity effect, downward sloping curve and price pressure view, the evidence appears to favour the information effect as the primary explanation for the permanent abnormal return for the complete period and the first period. This study documents a decrease in the percentage of mutual fund shareholding and a significant increase in the percentage of non-Mutual Fund shareholding (which includes retail investors).This along with increased liquidity, without abnormal volume, may be attributable to the increase in investor awareness, greater market scrutiny and certification.

This study also extends the previous empirical literature on Nifty index additions to the recent (2010 -2018) period as it reflects the current economic environment. The results show that index addition effect, though significant, has diminished in the second sub period. The downward sloping demand curve appears to be the dominant explanation for the evidenced significant permanent abnormal return in the second period. The evidence in favour of the price pressure hypothesis, relevant around the actual inclusion date, is limited.

The findings in the paper are not consistent with the efficient market hypothesis. The evidence, of downward sloping demand curves for stocks in the Indian stock market, is important to investors and portfolio managers with exposure to the market as there is potential for profitable trading strategies. This result is also important to the regulators as they can evaluate their initiative towards investor protection, disclosure and corporate governance. The study has focused only on additions to the index and did not consider deletions from the index. Also the behavioural biases or corporate governance issues as the 
possible explanations for the index revision effects were not part of the study. These could be avenues for future research.

\section{Notes}

Note 1. As the sample size is small, three periods are not possible. However, I changed the sub period to 2000 -2010 and 2011- 2018 and evidenced similar sub period results.

Note

https://www.sebi.gov.in/media/speeches/mar-2004/a-historical-perspective-of-the-securitiesmarket-reforms_2882.html.

https://www.nseindia.com/education/content/prs_publications.htm

The index funds including ETF were 10 in number in 2003. It increased to 32 in 2011 and 67 in 2017.

Note 3. According to World Federation of Exchanges (WFE)

Note 4. Source-NSE website, www.nseindia.com

Note 5. I did not study deletions from Nifty index as the focus of this study is Nifty index additions only. It is also difficult to get reasonable sized 'clean' sample as comparatively more deletions happen due to mergers, acquisitions and financial distress.

Note 6. The Indian studies evidencing lack of permanent abnormal returns have all used OLS market model with estimation period very similar to this study

Note 7. Nine added Stocks with alphas greater than $0.2 \%$ were part of the adjusted sample.

Note 8. Lynch and Mendenhall (1987) used returns from 872 to 673 days prior to AD. This period was not used in this study lest the sample size become even smaller due to lack of data.

Note 9. Nifty Junior index is now called 'Nifty Next 50 index' is next only to Nifty index in terms of market capitalization and liquidity in the Indian stock market.

Note 10. Volume in this study is the number of shares traded. The stock volume is standarised using the total NSE market volume. The calculation of volume ratio takes into account the capitalization changes

Note 11. Amihud (2002) employed the illiquidity measure, whereas this study uses the reciprocal ie. Liquidity measure

Note 12. The rationale behind the choice of $A D$ window $(A D+1$ to $A D+3)$ for the sub period I is the fraction of stocks for which $C A R>0$ is more than $50 \%$ for $A D+1, A D+2$ and $A D+3$ (Neither $\mathrm{AD}$ nor $\mathrm{AD}+4$ satisfied the above criterion for sub period I).

Note 13. All the regression results reported in this study are based on MCAR. However, this study evidenced similar results using CCAR and OCAR.

Note $14 . \mathrm{AD}+1$ and $\mathrm{AD}+1$ to $\mathrm{AD}+3$ results are similar to the reported $\mathrm{AD}+1$ to $\mathrm{AD}+2$ results. 


\section{Macrothink}

Asian Journal of Finance \& Accounting ISSN 1946-052X

Note 15. I also used mean VR of AD-10 to AD-4, AD-10 to AD-3 and evidenced similar results.

Note 16. Chen et al. and other studies analyse the number of shareholders and the number of trades. These data are not available in the NSE Indian official website for the complete period. The number of shareholders data and number of trades data are available only from 2007 and 2011 respectively. The total mutual fund data is used in this study due to non-availability of required index data.

Note 17 . When the mean percentage change in retail shareholding alone was considered, it was found to be negative and significant $-0.32 \%$ for sub period 2 and a positive $0.15 \%$ for sub period 1 corroborating the earlier evidence. 


\section{References}

Amihud, Y. (2002). Illiquidity and stock returns: Cross section and time series effects.Journal of Financial Markets, $\quad$ 5, 31-56. https://doi.org/10.1016/S1386-4181(01)00024-6

Amihud, Y., Mendelson, H., (1986). Asset pricing and the bid-ask spread, Journal of Financial Economics, 17(2), 223-249.

Barberis, N., Shliefer, A., Wurgler, J., (2005). Comovemen. Journal of Financial Economics, 75, 283-317.

Beneish, M. Gardner, J. (1995). Information costs and liquidity effects from changes in the Dow Jones industrial average list. Journal of Financial and Quantitative Analysis, 30, $135-137$

Beneish, M.D., Whaley, R.E., (1996). The anatomy of the S\&P game: The effect of changing rules, Journal of Finance, 51, 1909-1930.

Brown, S.J., Warner, J.B., (1985). Using daily stock returns: The case of event studies, Journal of Financial Economics, 14(1), 3-31.

Cai, J. and Houge, T., (2008). Long-term impact of Russell 2000 index rebalancing, Financial Analysts Journal, 64(4), 76-91. https://doi.org/10.2469/faj.v64.n4.7

Chakrabarti, R., Huang, W., Jayaraman, N., Lee, J., (2005). Price and volume effects of changes in the MSCI indices-nature and causes, Journal of Banking and Finance, 5, 1237-1264. https://doi.org/10.1016/j.jbankfin.2004.04.002

Chen, H., Noronha, G., Singhal, V., (2004). The price response to S\&P 500 additions and deletions: Evidence of asymmetry and a new explanation, Journal of Finance, 59(4),1901-1929.

Daya, W., Mazouz, K. and Freeman, M., (2012). Information efficiency changes following FTSE 100 index revisions, Journal of International Financial Markets, Institutions and Money, 22(4), 1054-1069. https://doi.org/10.1016/j.intfin.2012.01.002

Denis, D.K., McConnell, J.J., Ovtchinnikov, A.V., Yu, Y., (2003). S\&P 500 Index additions and earnings expectations. Journal of Finance, 58(5), 1821-1840.

Dhillon, U., Johnson, H., (1991). Changes in the Standard and Poor's 500 list, Journal of Business, 64, 75-85.

Elliot, W., Van Ness, B., Walker, M., Warr, R., (2006). What drives the S\&P 500 inclusion effect?, An analytical survey. Financial Management, 35(4),31-48.

Fernandes, M., Mergulhão, J., (2016). Anticipatory effects in the FTSE 100 index revisions. Journal of Empirical Finance, 37, 79-90. https://doi.org/10.1016/j.jempfin.2016.02.009.

Gregoriou, A., Ioannidis, C. (2006). Information costs and liquidity effects from changes in the FTSE 100 list, The European Journal of Finance, 12(4), 347-360. 
Harris, L., \& Gurel, E. (1986). Price and volume effects associated with changes in the S\&P 500 list, New evidence for the existence of price pressures. Journal of Finance, 41, 815-829.

Hacibedel, B., (2008). Index changes in emerging markets. Swedish Institute of financial research working paper, saltmatagatan, 19A, SE-113, 59, Stockholm, Sweden.

Hacibedel, B. and van Bommel, J. (2007). Do emerging markets benefit from index inclusion?. In Money Macro and Finance (MMF) Research Group Conference 2006, 128.

Hegde, S. P. and J. B. McDermott (2003). The Liquidity Effects Of Revisions to the S\&P 500 Index: An Empirical Analysis. Journal of Financial Markets, 6(3), 413-459

Hrazdil, K., (2009). The price, liquidity and information asymmetry changes associated with new S\&P 500 additions. Managerial Finance, 3(7), 579-605. https://doi.org/10.1108/03074350910960337

Jain, P.C., (1987). The effect on stock price of inclusion in or exclusion from the S\&P 500 . Financial Analyst Journal, 43, 58-65.

Kamal, R., Lawrence, E.R., McCabe, G. Prakash, A.J., (2012). Additions to S\&P 500 Index: not so informative any more, Managerial Finance, 38(4), 380-402. https://doi.org/10.1108/03074350910960337

Kothari, S.P. and Warner, J.B. (2007). Econometrics of Event Studies. Handbook of Corporate Finance: Empirical Corporate Finance. B. EspenEckbo

Kumar, S.S.S., (2005), Price and volume effects of S\&P Nifty index reorganizations, NSE

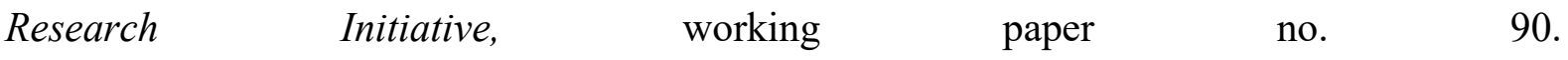
http://www.nseindia.com/content/research/comppaper90.pdf.

Lynch, A., Mendenhall, R. (1997). New evidence on stock price effects associated with changes in the S\&P 500. Journal of Business, 70, 351-384.

Mackinlay, A.C. (1997). Event studies in economics and finance, Journal of Economic Literature, 35(1), 13-39.

Merton, R.C. (1987). A simple model of capital market equilibrium with incomplete information. Journal of Finance, 42, 483-510.

Miller, C. and Ward, M. (2015). The market impact on shares entering or leaving JSE indices, Investment Analysts Journal, 44(1), 84-101. https://doi.org/10.1080/10293523.2015.994450.

Modigliani, F.; Miller, M. (1958). The Cost of Capital, Corporation Finance and the Theory of Investment. American Economic Review, 48(3), 261-297

Parthasarathy, S. (2010). Price and volume effects associated with Index additions-Evidence from the Indian stock market. Asian Journal of Finance and Accounting, 2(2), 55-76. https://doi.org/10.5296/ajfa.v2i2.469 
Rahman, A.Rajib, P., (2014). Associated effects of index composition changes: an evidence from the S\&P CNX Nifty 50 index. Managerial Finance, 40(4), 376-394. https://doi.org/10.1108/MF-01-2013-0010

Sharpe, W.F. (1964). Capital asset prices: A theory of market equilibrium under conditions of risk. Journal of Finance, 19(3), 425-442.

Shleifer, A. (1986). Do demand curve for stocks slope down? Journal of Finance, 41, 579-590.

Soe, A.M. and Dash, S. (2008). The Shrinking Index Effect: A Global Perspective, Available at SSRN 1568122.

Vespro, C., (2006). Stock price and volume effects associated with compositional changes in European stock indices. European Financial Management, 12(1), 103-127.

Wang, C., Murgulov, Z. and Haman, J. (2015). Impact of changes in the CSI 300 Index constituents, Emerging Markets Review, 24, 13-33. https://doi.org/10.1016/j.ememar.2015.05.005

Wurgler, J., Zhuravskaya, E. (2002). Does arbitrage flatten demand curve for stocks? Journal of Business, 75, 583-608. 
Appendix-1

\begin{tabular}{|c|c|c|c|}
\hline AD & Stock Symbol & ED & $\begin{array}{c}\text { Trading } \\
\text { days }\end{array}$ \\
\hline 24-Apr-00 & HCL-INSYS & 24-May-00 & 19 \\
\hline 24-Apr-00 & ZEETELE & 24-May-00 & 19 \\
\hline 20-Jul-00 & DIGITALEQP & 1-Sep-00 & 28 \\
\hline 26-Apr-00 & DABUR & 5-Oct-00 & 8 \\
\hline 6-Dec-01 & SUNPHARMA & 17-Jan-02 & 26 \\
\hline 6-Dec-01 & WIPRO & 17-Jan-02 & 26 \\
\hline 15-Apr-02 & VSNL & 31-May-02 & 31 \\
\hline 16-Sep-02 & $\mathrm{SCI}$ & $10-O c t-02$ & 15 \\
\hline 16-Sep-02 & BPCL & $28-O c t-02$ & 26 \\
\hline 16-Sep-02 & HCLTECH & 28-Oct-02 & 26 \\
\hline 13-Mar-03 & GAIL & 2-May-03 & 30 \\
\hline 13-Mar-03 & NATALUM & 2-May-03 & 30 \\
\hline 16-Jun-03 & SAIL & 4-Aug-03 & 33 \\
\hline 16-Jan-04 & BHARTIAIRTEL & 1-Mar-04 & 27 \\
\hline 26-Mar-04 & ONGC & 12-Apr-04 & 8 \\
\hline 12-Мay-06 & SIEMENS & 27-Jun-06 & 31 \\
\hline 20-Feb-07 & STER & 4-Apr-07 & 28 \\
\hline 10-Aug-07 & NTPC & 24-Sep-07 & 28 \\
\hline 11-Sep-07 & UNITECH & 5-Oct-07 & 15 \\
\hline 10-Feb-09 & AXISBANK & 27-Mar-09 & 28 \\
\hline 19-Мау-09 & JINDALSTEL & 17-Jun-09 & 19 \\
\hline 4-Sep-09 & JPASSOCIAT & 22-Oct-09 & 28 \\
\hline 4-Sep-09 & IDFC & 22-Oct-09 & 28 \\
\hline 24-Feb-10 & KOTAKBANK & 8-Apr-10 & 26 \\
\hline 19-Aug-10 & SESAGOA & $1-$ Oct-10 & 29 \\
\hline 19-Aug-10 & DRREDDY & $1-$ Oct-10 & 28 \\
\hline 19-Aug-10 & BAJAJAUTO & 1-Oct-10 & 28 \\
\hline 14-Mar-12 & ASIANPAINTS & 27-Apr-12 & 28 \\
\hline 14-Mar-12 & BANKBAR & 27-Apr-12 & 28 \\
\hline 16-Aug-12 & LUPIN & 28-Sep-12 & 28 \\
\hline 16-Aug-12 & ULTRATECH. & 28-Sep-12 & 28 \\
\hline 13-Feb-13 & INDUSIND & 1-Apr-13 & 29 \\
\hline 13-Feb-13 & NMDC & 1-Apr-13 & 29 \\
\hline 27-Feb-14 & TECHM & 28-Mar-14 & 19 \\
\hline 27-Feb-14 & MCDOWELL-N & 28-Mar-14 & 19 \\
\hline 21-Aug-14 & ZEEL & 19-Sep-14 & 18 \\
\hline $20-F e b-15$ & IDEA & 27-Mar-15 & 23 \\
\hline $20-F e b-15$ & YESBANK & 27-Mar-15 & 23 \\
\hline
\end{tabular}




\begin{tabular}{|c|c|c|c|}
\hline 29-Apr-15 & BOSCHLTD & 29-May-15 & 18 \\
\hline 12-Aug-15 & ADANIPORT & 28-Sep-15 & 29 \\
\hline $22-F e b-16$ & AUROPHARMA & 1-Apr-16 & 24 \\
\hline $22-F e b-16$ & INFRATEL & 1-Apr-16 & 24 \\
\hline $22-F e b-16$ & EICHERMOT & 1-Apr-16 & 24 \\
\hline 16-Feb-17 & INDBULHSG & 31-Mar-17 & 27 \\
\hline 16-Feb-17 & IOC & 31-Mar-17 & 27 \\
\hline 28-Aug-17 & BAJFINANCE & 29-Sep-17 & 22 \\
\hline 28-Aug-17 & HPCL & 29-Sep-17 & 22 \\
\hline 28-Aug-17 & UPL & 29-Sep-17 & 22 \\
\hline 21-Feb-18 & BAJFINSV & 2-Apr-18 & 27 \\
\hline 21-Feb-18 & TITAN & 2-Apr-18 & 27 \\
\hline
\end{tabular}

